\title{
Factors associated with receipt of mammogram among caregivers: a comparison with non-caregivers
}

\author{
Soo Young Kim", Yuqi Guo ${ }^{2,3^{*}}$ (D), Chorong Won ${ }^{4}$ and Hee Yun Lee ${ }^{4}$
}

\begin{abstract}
Background: caregiving responsibilities significantly impact females' decisions on adhering to preventive mammography. The purpose of this study is to examine (1) the levels of mammogram receipt, (2) the role of caregiving factors on the receipt of mammogram in caregiving group, and (3) the role of cancer beliefs on mammogram screening in caregivers and non-caregivers.
\end{abstract}

Methods: the 2017 Health Information National Trends Survey (HINTS) provides samples of 1228 women aged 40 to 75 years old for this secondary analysis. By using Andersen's Behavioral Model of Health Services Use, a binomial logistic regression model was used to analyze associations between mammography and socioeconomic factors, caregiving factors, and cancer belief factors.

Results: caregivers who provided more caregiving hours per week $(\mathrm{OR}=0.749,95 \% \mathrm{Cl}=0.564-0.94)$ and caregivers who had the belief of rather not knowing the likelihood of getting cancer $(\mathrm{OR}=0.673,95 \% \mathrm{Cl}=0.496-0.914)$ were less likely to use mammogram. However, caregivers who believed cancer is more common than heart disease $(\mathrm{OR}=1.490,95 \% \mathrm{Cl}=1.302-2.151)$ were more likely to use a mammogram. Non-caregivers who worried about getting cancer $(\mathrm{OR}=1.158,95 \% \mathrm{Cl}=0.793-1.691)$ were more likely to use mammogram, but non-caregivers who had the belief of rather not know the likelihood of getting cancer $(\mathrm{OR}=0.825,95 \% \mathrm{Cl}=0.713-0.955)$ were less likely to use mammogram.

Conclusions: to support caregivers' breast cancer prevention, caregiving-related policies based on caregiving hours should be developed. Particularly, effort to promote breast cancer screening education and care support among older primary caregivers will likely increase their adherence to preventive mammography uptake. The development of targeted cancer prevention interventions on specific cancer beliefs held by both groups are also urgently needed to promote mammography.

Keywords: Mammogram, Caregiver, Hours, Non-caregiver, Anderson behavioral model, Cancer beliefs

\footnotetext{
* Correspondence: yguo16@uncc.edu

${ }^{2}$ School of Social Work, College of Health and Human Services, University of North Carolina at Charlotte, Charlotte, North Carolina, USA

${ }^{3}$ School of Data Science, University of North Carolina at Charlotte, Charlotte, North Carolina, USA

Full list of author information is available at the end of the article
}

(C) The Author(s). 2020 Open Access This article is licensed under a Creative Commons Attribution 4.0 International License, which permits use, sharing, adaptation, distribution and reproduction in any medium or format, as long as you give appropriate credit to the original author(s) and the source, provide a link to the Creative Commons licence, and indicate if changes were made. The images or other third party material in this article are included in the article's Creative Commons licence, unless indicated otherwise in a credit line to the material. If material is not included in the article's Creative Commons licence and your intended use is not permitted by statutory regulation or exceeds the permitted use, you will need to obtain permission directly from the copyright holder. To view a copy of this licence, visit http://creativecommons.org/licenses/by/4.0/. The Creative Commons Public Domain Dedication waiver (http://creativecommons.org/publicdomain/zero/1.0/) applies to the data made available in this article, unless otherwise stated in a credit line to the data. 


\section{Background}

Breast cancer is the most common cancer and the second leading cause of cancer death among U.S. women [1]. In 2019, an estimated 268,600 new cases of invasive breast cancer and 62,930 new cases of non-invasive breast cancer were diagnosed in women in the U.S.; also, an estimated 41,760 women are expected to die from breast cancer [2]. Previous evidence suggested that the decrease in incidence and mortality rate was partially due to the extensive use of preventive mammograms, which offer early detection and treatment of breast cancer $[3,4]$. The latest American Cancer Society breast cancer screening guidelines recommend that "women ages 40 to 44 should have the choice to start annual breast cancer screening with mammograms if they wish to do so; women ages 45-54 should have yearly mammograms; and women ages 55 and older should switch to mammograms every 2 years or can continue yearly screening" [5]. However, getting recommended mammograms is one of the unmet health care among female caregivers [6]. Approximately $23.5 \%$ of female caregivers never received a mammogram, particularly [7, 8]. Notably, the difference in mammogram use behaviors between caregivers and non-caregivers is understudied.

Previous studies have reported relevant factors to mammogram use in both caregivers and non-caregiver. For example, age-related trends in mammogram use were observed in both caregivers and non-caregivers in previous studies [3, 9-11]. After 45 years of age, older women were more likely than younger women to have mammograms $[9,12]$. Also, cancer beliefs played a critical role in using mammograms. Cancer-related fear was common, which significantly impacted women's mammograms use [13]. Caregivers tended to be more familiar with cancer than non-caregivers [13-17]. However, noncaregivers seemed to be more attentive to cancer-related self-care and perceive a higher risk of breast cancer than caregivers, which leads to mammograms use [16]. People who have family cancer history, and caregivers of cancer survivors have increased odds in receiving mammograms $[18,19]$. In addition, depression is a risk factor for mammography underuse in general populations [20]. Women who are depressed are less likely to receive screening, and female caregivers are at risk of depression due to the heavy caregiver burden [20, 21].

Regarding caregiver-specific factors to mammography screening, previous studies showed mixed or limited results. For example, caregiver burden was identified as one of the barriers to screening [22, 23]. The authors proposed that caregivers who have caregiver procrastination and high burden may lead to less frequent breast examinations [23]; however, another study found no significant association [2]. Also, caregivers of cancer patients generally had an increased likelihood of receiving cancer preventive screenings [23, 24]. An increase of likelihood may be due to the high supply of cancer information from medical professionals, leading to increased awareness of preventive screenings [24]. In addition, financial matter was an aspect impacting mammography recipients [13]. However, no income-related disparities in mammography use have been observed between caregivers and non-caregivers in previous literature.

By using the Andersen's Behavioral Model of Health Services Use [25], our study compared mammogram screening behaviors between caregivers and noncaregivers to examine (1) the levels of mammogram receipt, (2) the role of caregiving factors, and (3) the role of cancer beliefs on mammogram screening of caregivers and non-caregivers. The hypotheses were:

1. The likelihood of using a mammogram would differently associate with predisposing factors (age, education, and beliefs about cancer) between caregivers and non-caregivers.

2. The likelihood of using a mammogram would differently associate with enabling factors (income, confidence about getting health information, and caregiving burden) between caregivers and noncaregivers.

3. The likelihood of using a mammogram would differently associate with need factors (general health, depression, and family cancer history) between caregivers and non-caregivers.

\section{Methods}

\section{Research design and data source}

This study analyzed data from the 2017 Health Information National Trends Survey (HINTS). HINTS 5's Cycle 1 (2017) data were collected from January to May, and a single-mode mail survey was generated [26]. According to the latest breast cancer screening guideline that women can start annual screening of mammograms at the age of 40 [5], our study included 1228 women aged 40 to 75 years as samples. The sample was categorized into two subgroups: caregivers and non-caregivers. Overall, the sample consisted of 277 caregiving women and 951 non-caregiving women aged 40 to75 years. More details about the development of HINTS have been reported elsewhere [26].

\section{Measurement}

Caregivers were defined as people who were caring for or making health care decisions for someone with a medical, behavioral, disability, or other condition whether caregiver or not was analyzed as a dichotomous variable $(0=$ no; 1 = yes $)$. 


\section{Dependent variable}

As National Comprehensive Cancer Network (NCCN) recommended yearly mammography to women ages 40 to 75 and the ACS also recommended women to start yearly mammography at the age of 40 and may continue yearly mammography up to the age of 75 , the dependent variable named mammogram screening measured whether a participant had received a mammogram within the past year (12 months). Participants' selfreported mammogram screening over the past 12 months was analyzed as a dichotomous variable $(0=$ did not have a recent mammogram screening; $1=$ had a recent mammogram screening).

\section{Independent variables}

Predisposing factors were age (40 to 75$)$, education ( $1=$ Less than 8 years to $7=$ Postgraduate), and beliefs about cancer. To assess cancer beliefs, the HINTS included eight items. Six items were assessed by asking respondents to rate on a 4 likert scale $(1=$ strongly disagree; $2=$ somewhat disagree; 3 = somewhat agree; $4=$ strongly agree) their cancer beliefs (it seems like everything causes cancer; there's not much you can do to lower your chances of getting cancer; there are so many different recommendations about preventing cancer, it's hard to know which ones to follow; cancer is more common than heart disease in adults; when I think about cancer, I automatically think about death; I'd rather not know my chance of getting cancer). Other items (how likely are you to get cancer in your lifetime; how worried are you about getting cancer?) were assessed by asking respondents to rate on a five-point scale ( 1 = very unlikely; $2=$ unlikely; $3=$ neither unlikely nor likely; 4 =likely; $5=$ very likely, $1=$ not at all; $2=$ slightly; $3=$ somewhat; $4=$ moderately; 5 = extremely).

Enabling factors were income $(1=\$ 0-9999$ to $9=$ $\geq \$ 200,000)$ and confidence about health information ( 1 = Not confident at all; 2 = A little confident; $3=$ Somewhat confident; $4=$ Very confident; $5=$ Completely confident). We included four additional items that are related to the caregiving characteristic for the caregiver group. The continuous variables included the number of people under their care, and the categorical variables included the caregiving hours per week $(1=<5 \mathrm{~h}$ per week; $2=5-14 \mathrm{~h}$ per week; $3=15-20 \mathrm{~h}$ per week, $4=$ $21-34$ h per week; $5=35$ or more hours per week), care receiver's cancer $(1=$ yes; $0=$ no), and care receiver's chronic illness $(1=$ yes; $0=$ no).

Need factors included four items (general health, depression, ever had cancer, and family ever had cancer). For self-rated health status, participants reported their general health status using a five-point Likert scale (1 = Poor; 2 = Fair; 3 = Good; 4 = Very Good; 5 = Excellent). HINTS contained four items related to depressive symptoms (little interest or pleasure in doing things; feeling down, depressed, or hopeless; feeling nervous, anxious, or on edge; not being able to stop or control worrying). We constructed a depression score by adding a value for the four items that ranged from "not at all" (1) to "nearly every day" (4). We also categorized caregiver's "Ever had cancer" and "family ever had cancer" to "yes" (1) or "no" (0).

\section{Data analysis}

General characteristics of caregivers and non-caregivers were described by calculating the frequencies, percentages, averages, and standard deviations. We examined the association between independent variables and mammogram screening behavior by conducting a crosstabulation analysis. Finally, we estimated a binomial logistic regression model that included predisposing, enabling, and need factors as independent variables and dichotomous indicators of mammogram screening behavior as the dependent variable. All analyses incorporated replicated sampling weights provided by HINTS to generate unbiased estimates and were conducted using the Stata 12.0 software package.

\section{Results}

Characteristics of the sample and rates of mammography

First, Table 1 describes the characteristics of our study sample. Of the 277 in the caregiver group, 176(63.5\%) received mammogram screenings. Of the 951 in the non-caregiver group, 601(63.3\%) received mammogram screening. Caregivers were younger ( 56.3 years old, SD = 9.315) than non-caregivers (58.6, $\mathrm{SD}=9.222$ ). About $72.4 \%$ of the caregiver group had completed some college and higher education, while $33.4 \%$ of the noncaregiver group had a high school diploma or less. The majority of both groups reported their health as more than good and not ever having had cancer. The average depression level was higher among the caregiver group $(6.291, \mathrm{SD}=3.192)$ than the non-caregiver group $(6.008$, $\mathrm{SD}=2.959)$. Two-fifths of participants in both groups reported that their family members have had cancer. More than two-thirds were caring for more than two persons, and most of the caregivers $(92.8 \%)$ were providing care for less than $20 \mathrm{~h}$ per week. Of the caregiver group, $18.8 \%$ have provided care for cancer patients, and 38.5\% have provided care for patients who have chronic conditions.

About $18.5 \%$ of the caregiver group thought that they were unlikely or very unlikely to get cancer in their lifetime, and about $68.4 \%$ agreed that it seemed like everything could cause cancer. Moreover, nearly 26\% of participants reported that there was not much they could do to lower their likelihood of getting cancer, and $75 \%$ agreed that there were so many different recommendations about cancer prevention that it was difficult to know which to follow. Nearly half of participants 
Table 1 Demographic Characteristics of Caregiver Samples and Non-Caregiver Samples

\begin{tabular}{lllll}
\hline Variables & \multicolumn{4}{l}{ Caregiver $(n=277)$} \\
\cline { 2 - 5 } & $\begin{array}{l}\text { Frequency } \\
(\%)\end{array}$ & \multicolumn{2}{l}{ Screening } \\
\cline { 3 - 5 } & & $\begin{array}{l}\text { No } \\
(\%)\end{array}$ & $\begin{array}{l}\text { Yes } \\
(\%)\end{array}$ & $x^{2}$ \\
\hline Dependent Variable & & &
\end{tabular}

Non-Caregiver $(n=951)$

Frequency Screening

(\%)

No Yes

(\%) (\%)

\section{Dependent Variable}

Mammogram Screening

\section{Predisposing factor}

Age

Education

$$
\text { High-school diploma or less }
$$

Some college and higher

Beliefs about cancer

Likelihood of getting cancer

Very unlikely and Unlikely

Neither unlikely nor likely

Likely and Very likely

Everything causes cancer

$$
\text { Agree }
$$

Disagree

Prevention is not possible

Agree

Disagree

Too many recommendations

Agree

Cancer more common

$$
\text { Agree }
$$

Disagree

Cancer fatal

Agree

Disagree

Rather not know the likelihood

$$
\text { Agree }
$$$$
\text { Disagree }
$$

$49(18.5)$
$121(45.7)$
$95(35.8)$

186(68.4)

86(31.6)

$70(26.2)$

197(73.8)

38.57

35.03

61.43

64.97

202(75.4)

34.16

66(24.6)

39.39

65.84

60.61

.5959

117(43.8)

150(56.2)

28.21

40.67

71.79

59.33

151(55.5)

121(44.5)

35.76

35.54

64.24

64.46

89(33.0)

39.33

$181(67.0)$

33.52

60.67

66.48

249(91.9)

37.75

22(8.1)

9.09

62.25

90.91

Enabling Factors

Income

$$
\$ 0-74,999
$$$$
\geq \$ 75,000
$$

171(67.1)

37.43

62.57

.0066

63.10

$4.4746^{*}$

421(46.6)

482(53.4)

.0015

524(57.0)

395(43.0)

.8818

$348(37.4)$

583(2.6)

Confident about getting health information

Very confident
Not very confident

155(58.3)

$111(41.7)$

29.68

43.24
$7.2583^{* *}$

875(93.9)

$57(6.1)$

\section{1(63.3)}

41.21
34.51

58.79

65.49
$4.0276^{*}$

34.51

Yes
$\%)$

$x^{2}$

$58.61(9.222)$

Caregiving Characteristic

Number of people under their care 
Table 1 Demographic Characteristics of Caregiver Samples and Non-Caregiver Samples (Continued)

\begin{tabular}{|c|c|c|c|c|c|c|c|c|}
\hline \multirow[t]{3}{*}{ Variables } & \multicolumn{4}{|c|}{ Caregiver $(n=277)$} & \multicolumn{4}{|c|}{ Non-Caregiver $(n=951)$} \\
\hline & \multirow{2}{*}{$\begin{array}{l}\text { Frequency } \\
\text { (\%) }\end{array}$} & \multicolumn{3}{|c|}{ Screening } & \multirow{2}{*}{$\begin{array}{l}\text { Frequency } \\
\text { (\%) }\end{array}$} & \multicolumn{3}{|c|}{ Screening } \\
\hline & & $\begin{array}{l}\text { No } \\
(\%)\end{array}$ & $\begin{array}{l}\text { Yes } \\
(\%)\end{array}$ & $x^{2}$ & & $\begin{array}{l}\text { No } \\
\text { (\%) }\end{array}$ & $\begin{array}{l}\text { Yes } \\
(\%)\end{array}$ & $x^{2}$ \\
\hline One & $82(33.7)$ & 39.02 & 60.98 & .8903 & - & - & - & - \\
\hline More than two or more & $161(66.3)$ & 32.92 & 67.08 & & - & - & - & - \\
\hline \multicolumn{9}{|l|}{ Caregiving hours per week } \\
\hline$<20 \mathrm{~h}$ per week & 180(92.8) & 33.89 & 66.11 & .4621 & - & - & - & - \\
\hline 21-34 h per week & $14(7.2)$ & 42,86 & 57.14 & & - & - & - & - \\
\hline \multicolumn{9}{|c|}{ Caregiving Cancer (Ref $=$ the others) } \\
\hline Yes & $55(18.8)$ & 34.29 & 65.71 & .0272 & - & - & - & - \\
\hline No & 238(81.2) & 35.71 & 64.29 & & - & - & - & - \\
\hline \multicolumn{9}{|c|}{ Caregiving Chronic (Ref $=$ the others) } \\
\hline Yes & 105(38.5) & 39.05 & 60.95 & .9211 & - & - & - & - \\
\hline No & $168(61.5)$ & 33.33 & 66.67 & & - & - & - & - \\
\hline \multicolumn{9}{|l|}{ Need factors } \\
\hline \multicolumn{9}{|l|}{ General Health } \\
\hline More than Good & $221(81.5)$ & 37.10 & 62.90 & 1.4774 & $752(80.3)$ & 34.31 & 65.69 & $9.4769^{* *}$ \\
\hline Less than Fair & $50(18.5)$ & 28.00 & 72.00 & & 185(19.7) & 46.49 & 53.51 & \\
\hline Depression & $6.291(3.192)$ & & & & $6.008(2.959)$ & & & \\
\hline \multicolumn{9}{|l|}{ Ever had cancer } \\
\hline Yes & $34(12.5)$ & 32.35 & 67.65 & .1713 & 172(18.3) & 29.65 & 70.35 & $4.5869^{*}$ \\
\hline No & 239(87.5) & 35.98 & 64.02 & & $769(81.7)$ & 38.36 & 61.64 & \\
\hline \multicolumn{9}{|l|}{ Family ever had cancer } \\
\hline Yes & 210(78.4) & 33.33 & 66.67 & 1.2920 & 696(77.3) & 34.20 & 65.80 & $5.4602^{*}$ \\
\hline No & $58(21.6)$ & 41.38 & 58.62 & & $204(22.7)$ & 43.14 & 56.86 & \\
\hline
\end{tabular}

Note: ${ }^{*} p<.05 ;{ }^{* *} p<.01,{ }^{* * *} p<.001$

reported that cancer is more common than heart disease (43.8\% of caregivers and $46.6 \%$ of non-caregivers), and when they think about cancer, they automatically think about death $55.5 \%$ of caregivers and $57.0 \%$ of noncaregivers). About $33 \%$ of caregivers and $37.4 \%$ of noncaregivers agreed that they would rather not know their likelihood of getting cancer. Most (91.9\% of caregivers and $93.9 \%$ of non-caregivers) participants in both groups reported that they were not extremely worried about getting cancer. About $67.1 \%$ of the caregiver group and $65.9 \%$ of the non-caregiver group members earned $<\$ 75$, 000 per year. About $60 \%$ of both groups reported that they felt confident about getting health information.

As can be seen by the cross-tabulated frequencies in Table 1, there were significant relationships between perceiving cancer as more common than heart disease $\left(\mathrm{X}_{2}=\right.$ 4.4746, $p<0.05)$, worries about cancer $(x 2=7.2583, p<$ $0.01)$, confidence about getting health information $\left(\mathrm{x}^{2}=\right.$ $5.2092, p<0.05)$, and getting mammogram screenings in the caregiver group. Moreover, in Table 1, there were significant relationships between education $\left(x_{2} 2=4.0276, p<\right.$
$0.05)$, rather not know the likelihood ( $2=13.5159, p<$ $0.001)$, income $(x 2=5.0811, p<0.05)$, general health $\left(x_{2}=\right.$ 9.4769, $p<0.01)$, ever had cancer $(x 2=4.5869, p<0.05)$, family ever had cancer ( $x 2=5.4602, p<0.05)$, and taking mammogram screenings in the non-caregiver group.

\section{Multivariate analysis}

\section{Binominal logistic regression}

Estimates from the binominal logistic regression model presented in Table 2 show that mammogram screening was positively associated with age $(\mathrm{OR}=1.058,95 \% \mathrm{CI}=$ $1.022-1.095, \quad \mathrm{OR}=1.029, \quad 95 \% \mathrm{CI}=1.013-1.046)$ and negatively with "rather not know my likelihood of getting cancer" $(\mathrm{OR}=.673,95 \% \mathrm{CI}=0.496-0.914, \mathrm{OR}=$ $.825,95 \% \mathrm{CI}=0.713-0.955)$ for both groups. However, among the caregiving group, the dependent variable was positively associated with confidence in getting health information $(\mathrm{OR}=1.432,95 \% \mathrm{CI}=1.049-1.955)$ and "cancer is more common than heart disease" $(\mathrm{OR}=$ 1.490, 95\% CI $=1.032-2.151)$ and negatively associated with caregiving hours per week $(\mathrm{OR}=.749,95 \% \mathrm{CI}=$ 
Table 2 Logistic Regression on Receipt of Mammogram Screening by Caregiving and Non-Caregiving Group

\begin{tabular}{|c|c|c|c|c|c|c|}
\hline \multirow[t]{2}{*}{ Factors } & \multirow{2}{*}{\multicolumn{2}{|c|}{ Predictors }} & \multicolumn{2}{|c|}{ Caregiver } & \multicolumn{2}{|c|}{ Non-Caregiver } \\
\hline & & & OR & $95 \% \mathrm{Cl}$ & OR & $95 \% \mathrm{Cl}$ \\
\hline \multirow[t]{10}{*}{ Predisposing factors } & \multicolumn{2}{|l|}{ Age } & $1.058^{* * *}$ & $1.022,1.095$ & $1.029^{* * *}$ & $1.013,1.046$ \\
\hline & \multicolumn{2}{|l|}{ Education } & 1.096 & $0.887,1.355$ & 1.093 & $0.980,1.218$ \\
\hline & \multirow[t]{8}{*}{ Beliefs about cancer } & Likelihood of getting cancer & 1.019 & $0.895,1.160$ & .932 & $0.866,1.003$ \\
\hline & & Everything causes cancer & .971 & $0.681,1.384$ & 1.183 & $0.983,1.423$ \\
\hline & & Prevention is not possible & .777 & $0.550,1.099$ & .989 & $0.823,1.188$ \\
\hline & & Too many recommendations & 1.158 & $0.793,1.691$ & 1.060 & $0.876,1.282$ \\
\hline & & Cancer more common & $1.490^{*}$ & $1.032,2.151$ & 1.126 & $0.939,1.349$ \\
\hline & & Cancer fatal & 1.200 & $0.854,1.685$ & .916 & $0.773,1.085$ \\
\hline & & Rather not know the likelihood & $.673^{*}$ & $0.496,0.914$ & $.825^{* *}$ & $0.713,0.955$ \\
\hline & & Worried about cancer & 1.213 & $0.916,1.606$ & $1.156^{*}$ & $1.000,1.337$ \\
\hline \multirow[t]{6}{*}{ Enabling Factors } & \multicolumn{2}{|l|}{ Income } & 1.074 & $0.927,1.243$ & 1.035 & $0.962,1.113$ \\
\hline & \multicolumn{2}{|c|}{ Confident about getting health information } & $1.432^{*}$ & $1.049,1.955$ & 1.021 & $0.868,1.201$ \\
\hline & \multicolumn{2}{|c|}{ Number of people under their care } & 1.523 & $0.889,2.609$ & - & - \\
\hline & \multicolumn{2}{|c|}{ Caregiving Hours per week } & $.749^{*}$ & $0.564,0.994$ & - & - \\
\hline & \multicolumn{2}{|c|}{ Caregiving Cancer (ref $=$ others) } & .735 & $0.306,1.769$ & - & - \\
\hline & \multicolumn{2}{|c|}{ Caregiving Chronic (ref = others) } & .657 & $0.370,1.166$ & - & - \\
\hline \multirow[t]{4}{*}{ Need factors } & \multicolumn{2}{|l|}{ General Health } & .803 & $0.571,1.128$ & 1.138 & $0.952,1.359$ \\
\hline & \multicolumn{2}{|l|}{ Depression } & 0.937 & $0.849,1.034$ & $.919^{* *}$ & $0.871,0.969$ \\
\hline & \multicolumn{2}{|l|}{ Ever had cancer } & 0.696 & $0.281,1.723$ & 1.351 & $0.899,2.030$ \\
\hline & \multicolumn{2}{|c|}{ Family ever had cancer } & 1.404 & $0.695,2.837$ & 1.344 & $0.956,1.891$ \\
\hline \multicolumn{3}{|c|}{ Number of observations } & 277 & & 951 & \\
\hline \multicolumn{3}{|c|}{ Pseudo $\mathrm{R}^{2}$} & 0.124 & & 0.057 & \\
\hline \multicolumn{3}{|c|}{ Log Likelihood Rate Test } & 43.05 & & 67.51 & \\
\hline
\end{tabular}

Note: ORs Odds ratios, ${ }^{*} p<.05 ;{ }^{* *} p<.01,{ }^{* * *} p<.001$

0.564-0.994). For the non-caregiver group, the dependent variable was positively associated with how worried they were about getting cancer (OR $=1.156$, 95\% $\mathrm{CI}=1.000-1.337)$ and negatively associated with depression $(\mathrm{OR}=.919,95 \% \mathrm{CI}=0.871-0.969)$.

\section{Discussion}

Our study results revealed similar mammogram screening rates for caregivers and non-caregivers $(63.5 \%$ vs. 63.3\%). Women caregivers within our sample did not neglect their breast cancer screening needs, which is consistent with the previous findings [17]. The findings of this study partially support our hypotheses. Age was identified as a positive factor for both groups, which is a promising finding in light of the importance of screening older women who are at increased risk for breast cancer. Previous studies have well documented that the risk of breast cancer increases with age [27]. The risk of having breast cancer increases after 40 years old and most breast cancers are diagnosed among older women who are 50 and older $[27,28]$.
Regarding predisposing factors, caregivers and noncaregivers identified different cancer belief factors associated with the utilization of mammograms. Among non-caregivers, the worry of getting cancer was a significant predictor of using mammograms. A recent study reported that women who worry about getting breast cancer were more willing to adhere to mammograms [29]. However, our study suggested that this knowledge could not be applied to caregiver populations.

In turn, caregivers identified the belief that cancer is more common than heart disease as a significant predictor in the utilization of mammograms. Also, access to health-related knowledge was positively associated with mammogram use among caregivers. The heightened level of health-related knowledge due to caregiving experience and easier access to medical professionals may help caregivers receive mammograms [23].

In addition, unwilling to know their possibility of getting cancer was a significant predictor of using mammograms for both caregivers and non-caregivers. The majority of the respondents did not want to know their likelihood of getting cancer and associated cancer-related 
death. These findings add to evidence that fear of having cancer is a significant predictor of not receiving a mammogram, which is supported by a previous study [30].

For enabling factors, mammogram screening behavior was negatively associated with hours of caregiving among caregivers. Even though there was not a significant difference in mammography rates between caregivers and non-caregivers, disparities in mammogram use exist within caregivers' groups. Caregivers who have more caregiving hours per week were significantly less likely to use mammograms. One previous study found that female caregivers who provide more than $14 \mathrm{~h}$ per week of caregiving had significantly lower odds of receiving mammography [8]. The overwhelming caregiving hours led to the underuse of mammograms as they were not able to take time off to care for themselves [8].

Finally, regarding need factors, non-caregivers, who showed symptoms of depression, exhibited lower odds of having mammograms. Depression is a risk factor for the underuse of mammography because depression generally leads to self-care neglect, including using mammograms [31, 32]. In this analysis, no other need factor associated with mammogram use among caregivers at a significant level.

\section{Limitation}

Our study had several limitations. First, as a secondary analysis, we were unable to examine the impact of details regarding the caregiving situation on mammogram screening behaviors. Even though the HINTS provided essential information on caregiving status, the information on caregiving duration and situation is lacked, such as hours of caregiving, the reason for caregiving, and relationship to the care recipients. However, our study is also strengthened by the high quality of the HINTS, its sampling procedures, and nationally representative samples. Second, the effects of caregiving by race were unable to be examined. Racial disparities in mammography have been well documented for both caregivers and general women [33, 34]. Our study focused on comparing mammogram screening behaviors between caregivers and non-caregivers. Third, our study was unable to compare mammogram use between women caregivers and non-caregivers with a 24-month time frame for repeated screening, given the possible differences in advice among women ages 40 to 44 and women ages 55 years older receive.

\section{Conclusion}

Our results demonstrate that there was no difference in receipt rates of mammograms between caregivers and non-caregivers. However, when considering caregiving status, women who need to spend more hours on caregiving may neglect their breast cancer screening needs.
Policymakers should consider providing free respite care service or preventive-care-related time off work to facilitate caregivers' early detection of breast cancer. Also, the effects of different cancer beliefs (e.g. rather not know the screening results; worry about cancers) on mammography behaviors varied between caregivers and noncaregivers. Education programs on breast cancer care and mammograms need to be designed with considering participants' caregiver status. For caregivers, education should focus on the importance of early detection of cancer survival. For non-caregivers, education should focus on reducing the fear of cancer. Future studies may analyze the caregiving roles on repeated mammograms (yearly or bi-yearly) with age-stratified samples.

\section{Abbreviations}

HINTS: Health Information National Trends Survey

\section{Acknowledgements}

Not applicable.

\section{Authors' contributions}

SK, YG, and HYL contributed to conceptualization. SK, YG, and HYL contributed to methodology. SK, YG, and HYL contributed to validation. SK performed formal analysis. SK and YG wrote the original paper. SK, YG, HYL, and $C W$ reviewed, and edited the paper. HYL supervised and contributed to funding acquisition. All authors have read and approved the manuscript.

Funding

This research was funded by the Endowed Research Fund from the University of Alabama School of Social Work to the last author.

Availability of data and materials

Health Information National Trends Survey is a public use dataset that is available from https://hints.cancer.gov/data/default.aspx.

Ethics approval and consent to participate

This secondary analysis used public use data that does not require ethics approval.

Consent for publication

Not applicable.

Competing interests

None declared.

\section{Author details}

${ }^{1}$ Department of Aging and Social Work, College of Nursing, Catholic University of Pusan, Busan, South Korea. ${ }^{2}$ School of Social Work, College of Health and Human Services, University of North Carolina at Charlotte, Charlotte, North Carolina, USA. ${ }^{3}$ School of Data Science, University of North Carolina at Charlotte, Charlotte, North Carolina, USA. ${ }^{4}$ School of Social Work, University of Alabama, TUSCALOOSA, Alabama, USA.

Received: 23 January 2020 Accepted: 17 September 2020

Published online: 29 September 2020

\section{References}

1. Howlader N, Noone AM, Krapcho M, Miller D, Brest A, Yu M, Ruhl J, Tatalovich Z, Mariotto A, Lewis DR, Chen HS, Feuer EJ, Cronin KA (eds). SEERCancer Statistics Review, 1975-2017, National Cancer Institute. Bethesda, MD, https://seer.cancer.gov/csr/1975_2017/, based on November 2019 SEER data submission, posted to the SEER web site, April 2020.

2. U.S. Breast Cancer Statistics. Retrieved March 20, 2019, from https://www. breastcancer.org/symptoms/understand_bc/statistics. 
3. Gierisch JM, O'Neill SC, Rimer BK, DeFrank JT, Bowling JM, Skinner CS. Factors associated with annual-interval mammography for women in their 40s. Cancer Epidemiol. 2009;33(1):72-8. https:/doi.org/10.1016/j.cdp.2009.03.001.

4. Wirtz HS, Boudreau DM, Gralow JR, Barlow WE, Gray S, Bowles EJA, Buist DSM. Factors associated with long-term adherence to annual surveillance mammography among breast cancer survivors. Breast Cancer Res Treat. 2014;143(3):541-50. https://doi.org/10.1007/s10549-013-2816-3.

5. Smith, RA, Andrews, KS, Brooks D, Brawley OW, Saslow D, Fedewa SA, Wender RC. Cancer screening in the United States, 2018: a review of current American Cancer Society guidelines and current issues in cancer screening. C.a. Cancer J Clin 2018;68(4):297-316. https://doi.org/10.3322/caac.21446.

6. Fowler BA. Social processes used by African American women in making decisions about mammography screening. J Nurs Scholarsh. 2006;38(3):24754. https://doi.org/10.1111/j.1547-5069.2006.00110.x.

7. Bradley PJ. Family caregiver assessment: essential for effective home health care. J Gerontol Nurs. 2003;29(2):29-36. https://doi.org/10.3928/0098-913420030201-08.

8. Kim C, Kabeto MU, Wallace RB, Langa KM. Quality of preventive clinical services among caregivers in the health and retirement study. J Gen Intern Med. 2004;19(8):875-8. https://doi.org/10.1111/j.1525-1497.2004.30411.x.

9. Hiatt RA, Pasick RJ, Stewart S, Bloom J, Davis P, Gardiner P, Stroud F. Community-based cancer screening for underserved women: design and baseline findings from the breast and cervical Cancer intervention study. Prev Med. 2001;33(3):190-203. https://doi.org/10.1006/pmed.2001.0871.

10. Husaini BA, Sherkat DE, Bragg R, Levine R, Emerson JS, Mentes CM, Cain VA. Predictors of breast Cancer screening in a panel study of African American women. Women Health. 2001;34(3):35-51. https://doi.org/10.1300/ J013v34n03_03.

11. Maxwell AE, Bastani R, Warda US. Demographic predictors of cancer screening among Filipino and Korean immigrants in the United States. Am J Prev Med. 2000;18(1):62-8. https://doi.org/10.1016/S0749-3797(99)00110-5.

12. Burg MA, Lane DS, Polednak AP. Age group differences in the use of breast Cancer screening tests. J Aging Health. 1990;2(4):514-30. https://doi.org/10. $1177 / 089826439000200406$.

13. McCaffery K, Forrest S, Waller J, Desai M, Szarewski A, Wardle J. Attitudes towards HPV testing: a qualitative study of beliefs among Indian, Pakistani, African-Caribbean and white British women in the U.K. Br J Cancer. 2003; 88(1):42-6. https://doi.org/10.1038/sj.bjc.6600686.

14. Chua MST, Mok TSK, Kwan WH, Yeo W, Zee B. Knowledge, perceptions, and attitudes of Hong Kong Chinese women on screening mammography and early breast Cancer management. Breast J. 2005;11(1):52-6. https://doi.org/ 10.1111/j.1075-122X.2005.21480.X.

15. Juon HS, Kim M, Shankar S, Han W. Predictors of adherence to screening mammography among Korean American women. Prev Med. 2004:39(3): 474-81. https://doi.org/10.1016/j.ypmed.2004.05.006.

16. Yavan T, Akyüz A, Tosun N, lyigun E. Women's breast cancer risk perception and attitudes toward screening tests. J Psychosoc Oncol. 2010. https://doi. org/10.1080/07347330903570453.

17. Chang BL, Sarna L, Carter PA. Mammography screening behavior in older women caregivers. Geriatr Nurs. 2001;22(1):33-6. https://doi.org/10.1067/ MGN.2001.113531.

18. Duffy SW, Morrish OWE, Allgood PC, Black R, Gillan MGC, Willsher P, Gilbert FJ. Mammographic density and breast cancer risk in breast screening assessment cases and women with a family history of breast cancer. Eur J Cancer. 2018;88:48-56. https://doi.org/10.1016/J.EJCA.2017.10.022.

19. Murabito JM, Evans JC, Larson MG, Kreger BE, Splansky GL, Freund KM, Wilson PWF. Family breast Cancer history and mammography: Framingham offspring study. Am J Epidemiol. 2001;154(10):916-23. https://doi.org/10. 1093/aje/154.10.916.

20. Demb J, Akinyemiju T, Allen I, Onega T, Hiatt RA, Braithwaite D. Screening mammography use in older women according to health status: a systematic review and meta-analysis. Clin Interv Aging. 2018;13:1987-97. https://doi.org/10.2147/CIA.S171739.

21. Ludman EJ, Ichikawa LE, Simon GE, Rohde P, Arterburn D, Operskalski BH, Jeffery RW. Breast and cervical cancer screening specific effects of depression and obesity. Am J Prev Med. 2010;38(3):303-10. https://doi.org/ 10.1016/j.amepre.2009.10.039.

22. Inoue M, Pickard JG, Welch-Saleeby P, Johnson S. African-American caregivers' breast health behavior. Health Educ Res. 2009;24(5):735-47. https://doi.org/10.1093/her/cyp008.
23. Reeves KW, Bacon K, Fredman L. Caregiving associated with selected cancer risk behaviors and screening utilization among women: Cross-sectional results of the 2009 BRFSS. BMC Public Health. 2012;12(685). https://doi.org/ 10.1186/1471-2458-12-685.

24. Keating NL, Landrum MB, Guadagnoli E, Winer EP, Ayanian JZ. Factors related to underuse of surveillance mammography among breast cancer survivors. J Clin Oncol. 2006;24(1):85-94. https://doi.org/10.1200/JCO.2005.02.4174.

25. Andersen RM. Revisiting the behavioral model and access to medical care: does it matter? J Health Soc Behav. 1995;36(1):1-10 Retrieved from http:// www.ncbi.nlm.nih.gov/pubmed/7738325.

26. Cantor D, Coa K, Crystal-Mansour S, Davis T, Dipko S, Sigman R. Health information national trends survey (HINTS) 2007. Westat: Rockville; 2009

27. Kelsey JL, Gammon MD, John EM. Reproductive factors and breast cancer. Epidemiol Rev. 1993;15(1):36.

28. McCormack VA, dos Santos Silva I. Breast density and parenchymal patterns as markers of breast cancer risk: a meta-analysis. Cancer Epidemiol Prev Biomarkers. 2006;15(6):1159-69.

29. Guan Y, Nehl E, Pencea I, Condit CM, Escoffery C, Bellcross CA, McBride CM. Willingness to decrease mammogram frequency among women at low risk for hereditary breast cancer. Sci Rep. 2019;9(1):9599.

30. Peek ME, Sayad JV, Markwardt R. Fear, fatalism and breast cancer screening in low-income African-American women: the role of clinicians and the health care system. J Gen Intern Med. 2008;23(11):1847-53.

31. Patten SB, Williams JV, Lavorato $\mathrm{DH}$, Eliasziw $\mathrm{M}$. The effect of major depression on participation in preventive health care activities. BMC Public Health. 2009;9(1):87

32. Mitchell AJ, Santo Pereira IE, Yadegarfar M, Pepereke S, Mugadza V, Stubbs B. Breast cancer screening in women with mental illness: comparative metaanalysis of mammography uptake. Br J Psychiatry. 2014;205(6):428-35.

33. Im EO, Park YS, Lee EO, Yun SN. Korean women's attitudes toward breast cancer screening tests. Int J Nurs Stud. 2004. https://doi.org/10.1016/j. ijnurstu.2004.01.004.

34. Sterba KR, Burris JL, Heiney SP, Ruppel MB, Ford ME, Zapka J. We both just trusted and leaned on the Lord: a qualitative study of religiousness and spirituality among African American breast cancer survivors and their caregivers Qual Life Res. 2014;23(7):1909-20. https://doi.org/10.1007/s11136-014-0654-3.

\section{Publisher's Note}

Springer Nature remains neutral with regard to jurisdictional claims in published maps and institutional affiliations.
Ready to submit your research? Choose BMC and benefit from:
- fast, convenient online submission
- thorough peer review by experienced researchers in your field
- rapid publication on acceptance
- support for research data, including large and complex data types
- gold Open Access which fosters wider collaboration and increased citations
- maximum visibility for your research: over $100 \mathrm{M}$ website views per year
At BMC, research is always in progress. 